\title{
A comparative analysis of monetary responses to global oil price changes: Net oil producing vs. net oil consuming countries
}

\author{
M. Ali Sotoudeh (correspondent) \\ Griffith Business School, Griffith University/Department of Economics, University of Sistan and Baluchestan \\ 170 Kessels Road, Nathan, QLD 4115, Australia \\ Phone: +61 (0)7 37357671 \\ Fax: +61 (0)7 37357177
}

Andrew C. Worthington

Griffith Business School, Griffith University, Australia

\begin{abstract}
In this paper, we examine monetary responses to global oil price changes across a panel of seven major net oil consuming countries and three major net oil producing countries using monthly data from January 1986 to August 2013. Employing a variety of linear and nonlinear causality tests, our main findings are as follows. First, oil price movements directly affect monetary aggregates in both net oil consuming and net oil producing countries. Second, nonlinear causality tests reveal strong causal influences from oil prices to monetary aggregates. Third, nonlinear parametric and nonparametric models reveal oil price changes account for significant changes in monetary aggregates in Denmark, Germany, the Netherlands, and the US among net oil consuming countries and in Canada and Mexico among net oil producing countries. Finally, monetary aggregates in these countries respond nonlinearly only to oil price increases.
\end{abstract}

Keywords: Oil price, monetary aggregate, oil consuming and oil producing countries, nonlinear causality tests.

JEL classification E52 E63 $\cdot \mathrm{N} 10 \cdot \mathrm{Q} 43$

\section{Introduction}

The study of the effects of oil price changes on economies dates back at least to the early 1970s when the 73/74 oil crisis was associated with severe economic recession throughout much of the world. Following Hamilton's (1983) seminal work on the oil price-recession relationship, a large number of studies have considered oil price changes and their possible interaction with other macroeconomic variables (e.g., Bruno and Sachs, 1985; Barsky and Kilian, 2004; Hamilton, 1996, 2003; Hooker, 1996; Kilian, 2008, 2009; Kilian and Park, 2009). Since then, major oil price shocks have triggered the significant intersectoral reallocation of resources, and afterwards in key economic variables such as monetary flow (e.g., Davis and Haltiwanger, 2001; Hamilton, 1988; Jones et al., 2004; Keane and Prasad, 1996; Lee and Ni, 2002). Studies that conclude that oil price shocks induce recession through different direct and indirect channels, mostly regard monetary tools as indirect mechanisms for this effect (e.g., Barsky and Kilian, 2004; Bernanke et al., 1997; Cologni and Manera, 2008; Hamilton, 2011; Hooker, 1999). 
However, few of these existing studies consider these mechanisms in countries outside the US or in oil-exporting countries. For example, oil price decreases positively affect economic activity in oilimporting countries, whereas such effects may be either positive or negative in oil-exporting countries (see e.g., Jiménez-Rodríguez and Sánchez, 2005). As another example, Korhonen and Ledyaeva (2010) show that oil-producing countries tend to generally benefit from oil price shocks, while the effects in oil-consuming countries are rather more ambiguous. Consequently, monetary responses to oil price changes may differ for oil importing and exporting countries.

Theoretically, increasing oil prices within oil importing countries leads consumers to expect that such variations are transitory and hence they save less and borrow (and spend) more. The subsequent increase in demand exerts pressure on the price index, in response to which central banks tighten the money supply to control the price level. In oil exporting countries, however, an increase in the oil price is mainly a supply-side change in that the positive income effect of the oil price increase injects money into the economy. Thus, increasing oil prices are contractionary in oil importing countries and expansionary in oil exporting countries. The reverse holds for a decrease in the oil price. However, the empirical evidence supporting these theoretical effects in a combined study of oil consuming and oil producing countries is very limited.

Most studies in this area consider monetary variables as a transmission channel between oil price shocks and the economy (e.g., Barsky and Kilian, 2004; Bernanke and Ilian, 1998; Bernanke et al., 1997; Cologni and Manera, 2008; Hamilton, 2011; Hooker, 1999; Hoover and Perez, 1994; Leduc and Sill, 2004). For instance, Leduc and Sill (2004) showed that monetary policy is responsible for about 40 percent of the reduction in output from an increase in the oil price. However, other studies analysed monetary responses to the oil price shocks either separately or associated with other related variables, such as interest or exchange rates (e.g., Abderrezak, 2005; Balke et al., 1998; Jones et al., 2004; Lee et al., 2001; Leeper and Zha, 2003; Miguel et al., 2009; Wu and Ni, 2011). All these findings justify the importance of implementing monetary policy in association with oil price volatility.

However, a few studies have considered the causal effects of the oil price changes on monetary factors. In seminal work, Bernanke et al. (1997) used vector auto-regressive (VAR) specifications to show that the US monetary response to oil price shocks was more significant than any other economic variable, concluding that it was the monetary changes which causes the declines in GDP growth, not the oil price shocks themselves. Likewise, Lee et al. (2001) found that monetary tightening resulting from oil price shocks was responsible for 30-50 percent of the negative changes in Japanese output. More recently, Wu and Ni (2011) concluded that the oil price Granger caused monetary aggregates in the US, arguing that as the monetary responses to the oil price changes take some time, finding the proper lag order was very important.

However, not all studies confirm the existence of meaningful relationships between oil price changes and monetary factors. Hamilton and Herrera (2004), in criticizing Bernanke et al. (1997), showed that the potential for monetary policy to avert the contractionary consequences of oil price shocks was not as great as Bernanke et al. (1997) suggested. Hamilton and Herrera (2004), Carlstrom and Fuerst (2006) also rejected the argument in Bernanke et al. (1997), showing that under neutral monetary policy, the entire output reduction associated with oil prices is due only to the oil price changes, and none of the declines is attributable to monetary policy. Finally, Abderrezak (2006) found no evidence of causation between oil price shocks and the money supply in Algeria. What we can conclude based on this rather mixed evidence is that further study is of great importance, especially as multicounty studies including both oil importers and oil exporters.

In this paper, we consider this question from several different perspectives. First, we use the notion of net oil consumption and net oil production instead of oil importing and oil exporting to identify countries. We believe this is a more nuanced way to identify the monetary effects of oil price shocks. For instance, based on International Energy Agency (IEA) figures, Canada produces more oil than Mexico and Mexico produces more oil than Norway. However, in terms of the oil production share of GDP, these countries would be ordered Norway, Mexico and Canada, while Norway exports more oil 
than Mexico and Mexico exports more oil than Canada. Likewise, the order of net oil consuming countries is not necessarily the same as their oil-importing ranking. We consider that such indices separate major net oil importers and exporters better as is based on both their exporting and importing behaviour and domestic consumption and production.

Second, we conduct both linear and nonlinear causality tests to identify any possible causal relationships between our sample variables. Although we start with traditional linear causality tests, the restrictive assumptions of linearity make these models inefficient in uncovering certain nonlinear causal relations, and hence, we are unable to detect all possible causal relations. Furthermore, a significant part of the literature allows for nonlinear causal relationships between the macroeconomic variables (e.g. Baek and Brock, 1992; Bell et al., 1996; Chen et al., 2004; Hiemstra and Jones, 1994; Hiemstra and Kramer, 1997; Li, 2006; Skalin and Teräsvirta, 1999).

Finally, as the direction of oil price change in the studied series has a significant effect on any causal relationships, we test this using the asymmetric version of the modified Mackey and Glass (1977) model. The results suggest that monetary aggregates respond to oil price changes asymmetrically, in both net oil consuming and net oil producing countries. That is, only positive changes in oil prices induce a significant nonlinear influence on monetary aggregates.

The remainder of the paper is organised as follows: Section 2 describes the data. Section 3 provides the the initial empirical results for conventional country-specific causality tests. Section 4 outlines the methodology of our modified parametric and nonparametric nonlinear causality models and presents the results. Section 5 presents the concluding remarks.

\section{Data}

Our sample data consist of oil prices and monetary aggregates in selected net oil consuming and net oil producing countries for the period January 1986-August 2013. Our sample selection criterion is the net oil production (consumption) share of GDP. Calculating this index for a wide range of oil-exporter and oil-importer countries and considering the availability of data, we identify the US, Brazil, Denmark, Italy, Germany, the Netherlands, and Sweden as major net oil consuming countries and Canada, Mexico and Norway as major net oil producing countries.

As a proxy for monetary aggregates (MA), following Jiménez-Rodríguez (2011), we use seasonally adjusted narrow money (M1), collected from the Organization for Economic Co-operation and Development (OECD) for Canada, Denmark, Mexico, Norway, Sweden, Brazil and the US. For Germany and Italy, we use statistics from the Deutsche Bundesbank and Banca d'Italia websites, respectively. We also collect M3 (as a proxy for M1) for Netherlands from the De Nederlandsche Bank. The monetary aggregate series for the last three countries are seasonally adjusted using X12-ARIMA method of the US Census Bureau. We deflate our data using domestic consumer price indices (CPI) from the OECD, and then index this series using the monthly-averaged 2010 series as the base year. The available data periods are shorter for Brazil, Italy, Sweden and Norway, with the sample period for Brazil commencing in August 1994, September 1997 for Italy, February 1998 for Sweden and December 1992 for Norway.

As a proxy for the world oil price index $(O P)$, we use monthly oil prices of West Texas Intermediate (WTI) crude oil, a very widely used oil pricing benchmark, not least given its strong correlation with the major other crude oil prices (Brent and Dubai) (Wang et al, 2013). We collect WTI price data from the World Bank website. Then, using the monthly US CPI index, collected from the OECD website, we calculate inflation-adjusted real oil prices. Finally, we index the oil prices using the monthly-averaged 2010 prices. 
Table 1 Selected statistics

\begin{tabular}{|c|c|c|c|c|}
\hline \multirow{2}{*}{ Country } & \multicolumn{2}{|c|}{ Mean } & \multicolumn{2}{|c|}{ SD } \\
\hline & Level & Difference & Level & Difference \\
\hline$M A$ & & & & \\
\hline Brazil & 51.6039 & 0.5342 & 36.0061 & 0.7271 \\
\hline Denmark & 36.9659 & 0.1969 & 32.1917 & 0.4409 \\
\hline Germany & 45.6237 & 0.2853 & 30.9992 & 1.2279 \\
\hline Italy & 72.3281 & 0.3193 & 20.8163 & 1.0144 \\
\hline Netherlands & 49.4390 & 0.2418 & 30.9713 & 1.0433 \\
\hline Sweden & 74.4005 & 0.3978 & 22.2382 & 0.4821 \\
\hline US & 52.6246 & 0.2575 & 31.4098 & 0.6453 \\
\hline Canada & 34.9059 & 0.2414 & 32.3588 & 0.3685 \\
\hline Norway & 63.3409 & 0.3766 & 30.5047 & 0.5909 \\
\hline Mexico & 36.7579 & 0.3937 & 40.5727 & 0.5700 \\
\hline$O P$ & 59.2783 & 0.2042 & 31.7885 & 5.5322 \\
\hline
\end{tabular}

This table provides statistics for the sample data. WTI real oil price deflated by US CPI. Countryspecific monetary aggregate (MA) series are seasonally adjusted and deflated using domestic CPIs. Data are monthly and indexed to constant inflation-adjusted 2010 year.

Table 1 presents statistics for the above data. As shown, the average monetary aggregate index ranges from 34.9 equivalents for Canada to 74.4 equivalents for Sweden. We also plot the time variations of the global oil price and monetary aggregate indices in Fig. 1. We find that the chosen monetary aggregate and the global oil price exhibit similar trends over time for all of the sample countries. This suggests potential causal relationships between the two variables.

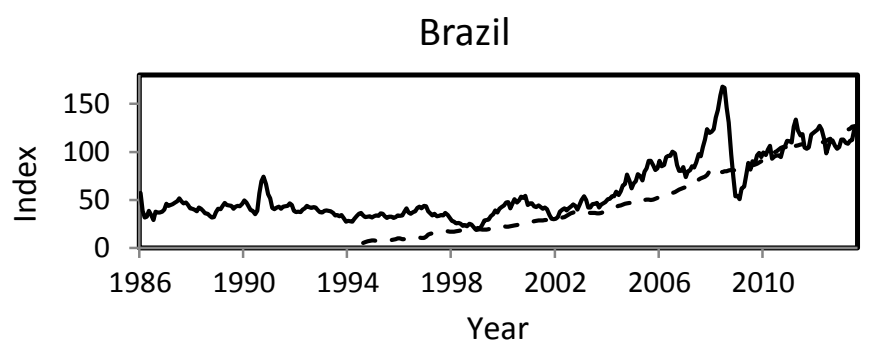

Denmark

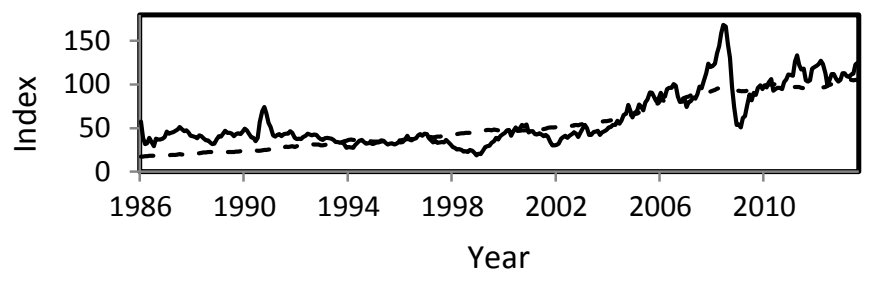

Germany

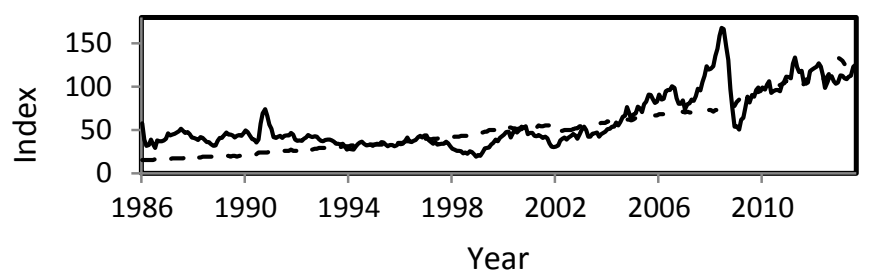

Sweden

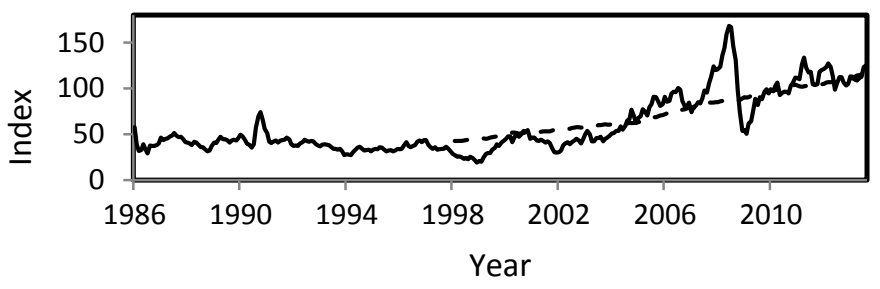

US

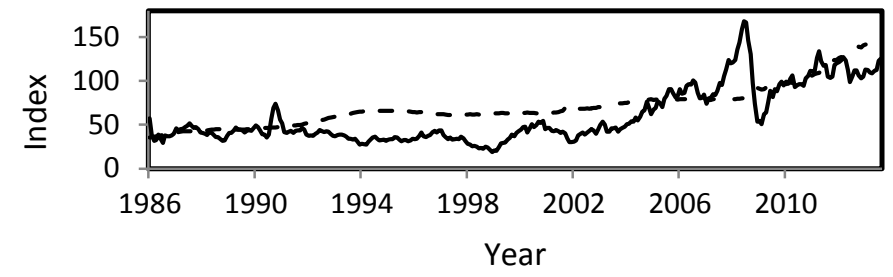

Canada

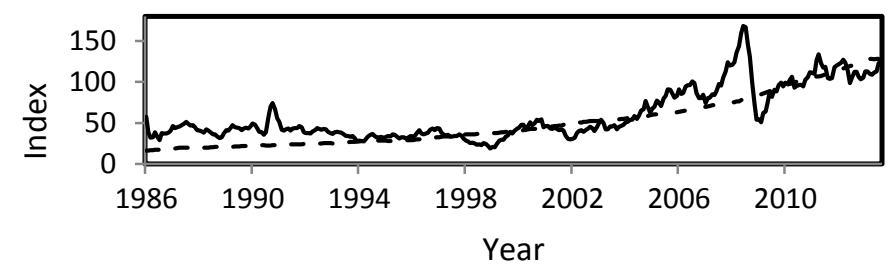


Italy

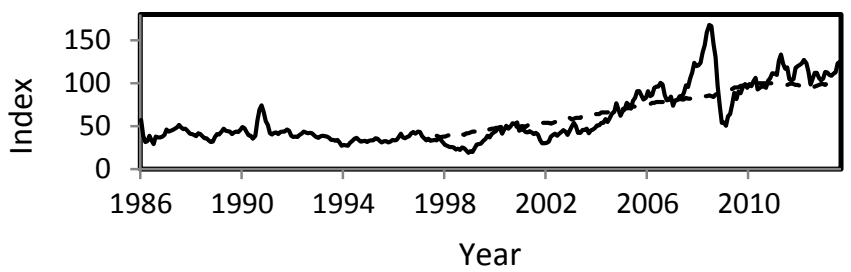

Netherlands

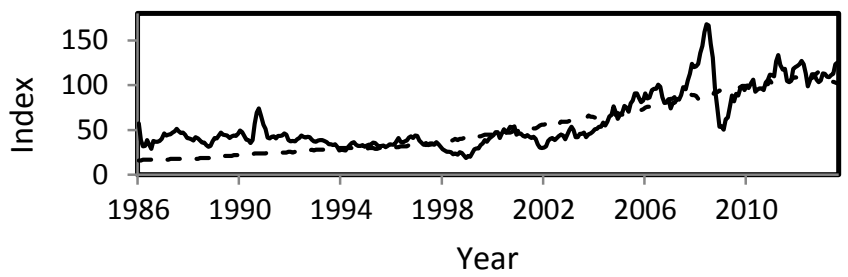

Norway

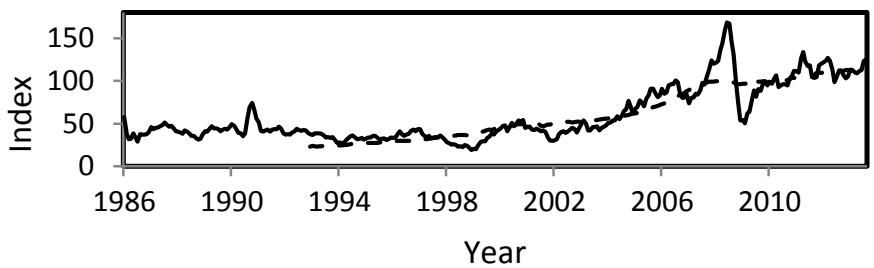

Mexico

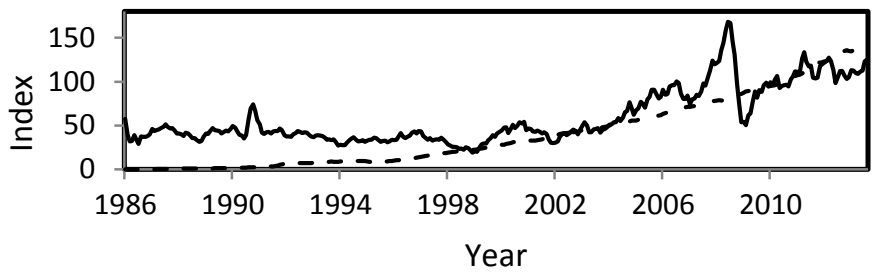

Fig 1. Oil prices and monetary aggregates by country

This figure depicts WTI real oil price (solid lines) deflated by US CPI. Country-specific monetary aggregate (dashed lines) are seasonally adjusted and deflated using domestic CPIs. The time dimension is shorter for Brazil, Italy, Sweden and Norway; it starts from August 1994, September 1997, February 1998 and December 1992, respectively.

\section{Traditional linear causality test}

To conduct the country-specific traditional linear causality test, we first need to consider our sample data order of integration. As a prerequisite, all data should be $I(0)$. Table 2 provides the results of the Augmented Dicky-Fuller (ADF) and Philips-Perron (PP) unit root tests. The ADF and PP tests indicate that the oil prices and monetary aggregates are integrated of order one, but their first differences are stationary. However, as the ADF and PP unit root tests are known to suffer potentially severe finite sample power and size problems (e.g., DeJong, 1992; Schwert, 1989), we employ additional unit root tests to check the robustness of the ADF and PP results, namely, the generalised least squares DickyFuller (DF-GLS) test. Other than Italy, we find evidence of nonstationary oil prices and monetary aggregates in levels while their first difference values are stationary. The test results show that our data series for all of sample countries, excepting Italy, are stationary in first differences.

Table 2 Unit root tests

\begin{tabular}{lcccccc}
\hline \multirow{2}{*}{ Country } & \multicolumn{2}{c}{ ADF } & \multicolumn{2}{c}{ DF-GLS } & PP \\
\cline { 2 - 7 } & Level & Fist difference & Level & $\begin{array}{c}\text { Fist } \\
\text { difference }\end{array}$ & Level & First difference \\
\hline Unit root test for MA & & & & & & \\
Brazil & 4.564 & $-9.139 * * *$ & -0.357 & $-2.551^{*}$ & 3.370 & $-9.036^{* * *}$ \\
Denmark & 5.447 & $-13.912^{* * *}$ & -0.360 & $-4.460^{* * *}$ & 3.446 & $-14.176^{* * *}$ \\
Germany & 3.114 & $-18.687^{* * *}$ & -0.057 & $-3.372 * *$ & 2.719 & $-18.939^{* * *}$ \\
Italy & -0.933 & $-18.974^{* * *}$ & $-2.853^{*}$ & -1.408 & -1.013 & $-18.730^{* * *}$ \\
Netherlands & 0.841 & $-19.351^{* * *}$ & -1.165 & $-2.231^{*}$ & 0.860 & $-19.350^{* * *}$ \\
Sweden & 2.615 & $-9.296^{* * *}$ & -0.596 & $-3.251^{*}$ & 2.258 & $-9.013^{* * *}$ \\
US & 7.995 & $-18.974^{* * *}$ & -1.268 & $-3.406^{* *}$ & 6.068 & $-20.179^{* * *}$ \\
Canada & 18.813 & $-13.019^{* * *}$ & -0.634 & $-2.555^{*}$ & 16.917 & $-13.628^{* * *}$ \\
Norway & 2.040 & $-8.994^{* * *}$ & -1.654 & $-2.554^{*}$ & 1.230 & $-8.971^{* * *}$ \\
Mexico & 15.072 & $-8.590^{* * *}$ & -0.188 & $-3.108^{* *}$ & 11.543 & $-8.618^{* * *}$ \\
Unit root test for OP & -0.905 & $-12.852^{* * *}$ & -1.172 & $-2.571^{*}$ & -1.563 & $-12.833^{* * *}$ \\
\hline
\end{tabular}


This table provides the results of the unit root tests for the monetary aggregate (MA) and global oil price (OP) for each country. The test statistics report rejection or acceptance of the null hypothesis of no Granger causality. T-test statistic used for ADF and PP tests and tau-test statistic used for DF-GLS test with proper lag order selected by Schwarz criterion. *, ** and *** indicate significance at the $10 \%, 5 \%$ and $1 \%$ level, respectively.

Table 3 reports the results of country-specific traditional Granger causality tests for the oil price and monetary aggregate relationship. The results indicate that global oil prices influence monetary aggregate of both net oil consuming and producing countries linearly in the same direction. The test statistics are significant, mainly at the 1 percent level. However, there is no evidence to confirm the causal effects of global oil price changes on the monetary aggregate in Brazil. The only difference could be found in causal relations between two panels of countries is that such relations are reported to be unidirectional within net oil producing countries while they are mostly bidirectional across net oil consuming countries. It seems that monetary changes in net oil consuming countries exhibit statistically significant causation over global oil price changes. One possible answer is the differences in the role of monetary change in the market. Given that consumers in net oil consuming countries consider oil price changes transitory, monetary reactions to oil price changes motivates aggregate demand. If such variations induce changes in productions of oil-intensive industries, there would be the possibility of exerting pressure on oil prices due to high demand for oil. Concerning above assumptions, the monetary causal effects on global oil price movements in net oil producing countries, however, seems to be less. The findings are consistent with Bernanke et al. (1997), Leduc and Sill (2004), Lee et al. (2001) and Wu and Ni (2011) in both net oil consuming and net oil producing countries. However, given our evidence implying the significant effects of global oil price changes on monetary aggregates in the US and other net oil consuming countries, our results do not align with those in Abderrezak (2006), Carlstrom and Fuerst (2006) and Hamilton and Herrera (2004).

Table 3 Traditional country-specific linear causality tests

\begin{tabular}{lcccccc}
\hline \multicolumn{1}{c}{$\Delta O P \rightarrow \Delta M A$} & \multicolumn{3}{c}{$\Delta M A \rightarrow \Delta O P$} \\
\hline \multicolumn{1}{c}{ Causality } & $\begin{array}{c}\text { Test statistic } \\
\text { (chi-square) }\end{array}$ & p-value & Result & $\begin{array}{c}\text { Test statistic } \\
\text { (chi-square) }\end{array}$ & p-value & Result \\
\hline Brazil & 5.3993 & 0.494 & Noncausality & $21.91^{* * *}$ & 0.001 & Causality \\
Denmark & $19.143^{* *}$ & 0.038 & Causality & $19.631^{* *}$ & 0.033 & Causality \\
Germany & $37.831^{* * *}$ & 0.000 & Causality & $18.671^{* * *}$ & 0.005 & Causality \\
Italy & $7.260^{*}$ & 0.064 & Causality & 4.095 & 0.663 & Noncausality \\
Netherlands & $31.011^{* * *}$ & 0.000 & Causality & 9.759 & 0.135 & Noncausality \\
Sweden & $10.935^{* *}$ & 0.050 & Causality & $10.331^{* *}$ & 0.066 & Causality \\
US & $25.495^{* * *}$ & 0.000 & Causality & 6.1447 & 0.407 & Noncausality \\
Canada & $45.381^{* * *}$ & 0.000 & Causality & 17.707 & 0.125 & Nonccausality \\
Norway & $12.929^{* *}$ & 0.044 & causality & 7.4016 & 0.285 & Non-causality \\
Mexico & $17.821^{* *}$ & 0.037 & causality & 4.3872 & 0.884 & Non-causality \\
\hline
\end{tabular}

This table presents the results for traditional linear Granger causality tests. The null hypothesis is noncausality. $* *$ and $* * *$ indicate significance at the $5 \%$ and $1 \%$ level, respectively.

Although our findings modify the existence of linear causation between global oil price changes and domestic monetary aggregates, there is still the possibility of nonlinear causation among these variables. Because of linearity assumptions in traditional Granger causality test, this model would not reveal certain nonlinear causations among variables. As Baek and Brock (1992), Bell et al. (1996), Chen et al. (2004), Hiemstra and Jones (1994), Hiemstra and Kramer (1997), Li (2006) and Skalin and Teräsvirta (1999) recommend, further nonlinear causality tests may reveal more detailed information about the 
nature of causation among the macroeconomic variables. In the following section, we consider nonlinear causality between our variables using two different models.

\section{Nonlinear causality tests}

The traditional Granger causality approach previously used compares the prediction errors obtained by a model that relates oil price changes to past and current values of both the monetary aggregate and the oil price. The advantage of this approach is its simplicity. However, two disadvantages are common. First, parametric tests require an important assumption regarding the linearity of the regression structure even though there is considerable evidence for nonlinearity among macroeconomic variables (see e.g., ChiouWei et al., 2008; Lee and Chang, 2007; Seifritz and Hodgkin, 1991). Second, because of the sensitivity of the prediction errors from linear Granger causality tests to causality in the mean, higher order structures, such as conditional heteroscedasticity, are usually precluded (Ajmi et al., 2013). Thus, nonlinear causality tests can better clarify the nature of the causal relationships between the variables. We employ two nonlinear Granger causality approaches. The first is a nonparametric model, introduced by Baek and Brock (1992) and modified by Hiemstra and Jones (1994). The second is a parametric model following Mackey and Glass (1977), modified by Kyrtsou and Labys (2006).

\subsection{Nonparametric model}

Our nonparametric nonlinear approach draws on Baek and Brock (1992). This method assumes that the variables are mutually independent and identically distributed. As this assumption seems quite restrictive in not considering time dependence, Hiemstra and Jones (1994) modified the model to include short-term temporal dependence in variables. Denote that $m$-length lead vector of $M A_{t}$ by $M A_{t}^{m}$ and the $L m a$-length and $L o p$-length lag vectors of $M A_{t}$ and $O P_{t}$ by $M A_{t-L m a}^{L m a}$ and $O P_{t-L o p}^{L o p}$. Thus:

$$
\begin{aligned}
& M A_{t}^{m}=\left(M A_{t}, M A_{t+1}, \ldots, M A_{t+m-1}\right) \\
& M A_{t-L m a}^{L m a}=\left(M A_{t-L m a}, M A_{t-L m a+1}, \ldots, M A_{t-1}\right) \\
& O P_{t-L o p}^{L o p}=\left(O P_{t-L o p}, O P_{t-L o p+1}, \ldots, O P_{t-1}\right)
\end{aligned}
$$

where $m=1,2, \ldots ; t=1,2, \ldots ; \operatorname{Lma}=1,2, \ldots, t$ and $\operatorname{Lop}=1,2, \ldots, t$. In the case of $M A, t=\operatorname{Lma}+$ $1, L m a+2, \ldots$ and in case of $O P, t=L o p+1, L o p+2, \ldots$. Based on definition delivered by Hiemstra and Jones (1994), for given values of $m, L m a, L o p \geq 0$ and for $e>0, O P$ does not strictly Granger cause $M A$ if:

$$
\begin{aligned}
& \operatorname{Pr}\left(\left\|M A_{t}^{m}-M A_{s}^{m}\right\|<e \mid\left\|M A_{t-L m a}^{L m a}-C P I_{s-L m a}^{L m a}\right\|<e,\left\|O P_{t-L o p}^{L o p}-O P_{s-L o p}^{L o p}\right\|<e\right) \\
& =\operatorname{Pr}\left(\left\|M A_{t}^{m}-M A_{s}^{m}\right\|<e \mid\left\|M A_{t-L c p i}^{L m a}-M A_{s-L c p i}^{L m a}\right\|<e\right)
\end{aligned}
$$

where $\operatorname{Pr}($.$) denotes the probability and \|\|$ refers to the maximum norm. The left-hand side of Equation 2 contains a conditional probability explaining two arbitrary $m$-length lead vector of $M A_{t}$ within a distance $e$ of each other when corresponding Lma-length lag vectors of $M A_{t}$ and Lop-length lag vectors of $O P_{t}$ are given. The right-hand side of Equation 2 describes the conditional probability that two arbitrary $m$-length lead vectors of $M A_{t}$ are within a distance $e$ of each other where their corresponding Lma-length lag vectors within a distance $e$ of each other are given. It is worth noting that for bivariate observable series $\left(O P_{t}\right.$ and $\left.M A_{t}\right), t=1, \ldots, T$, the Hiemstra-Jones test consists of choosing a value between 0.5 and 1.5 after normalizing the series to obtain unit variance. This allows us to estimate the conditional probabilities in Equation 2 as ratios of the unconditional probabilities. To test the nonlinear 
noncausality hypothesis presented in Equation 2, Hiemstra and Jones (1994) use the following statistic, which has an asymptotic normal distribution:

$$
\sqrt{n}\left(\frac{C_{1}(m+L m a, L o p, e, n)}{C_{2}(L m a, L o p, e, n)}-\frac{C_{3}(m+L m a, e, n)}{C_{4}(L m a, e, n)}\right) \sim N\left(0, \sigma^{2}(m, L m a, L o p, e)\right)
$$

where $n=T+1-m-\max (\operatorname{Lma}, L o p)$, and $C_{1}, C_{2}, C_{3}$ and $C_{4}$ are correlation integral estimators of the joint probabilities in Equation 2 and $\sigma^{2}$ is estimated based on the theory of the U-statistic for weakly dependent processes as measured by Denker and Keller (1983). This test statistic is applied to the estimated residuals of the bivariate VAR model, which employs $M A$ and $O P$. The test statistic, which is used to examine the null hypothesis, states that the oil price does not nonlinearly and strictly Grangercause the monetary aggregate. As Hiemstra and Jones (1994) and Kanas and Ma (2000) show, this model has a very good power in estimating nonlinear Granger causal and noncausal relationships.

To implement the nonparametric nonlinear causality test for the monetary aggregate and oil price, we first need to determine the values of the lead lengths, the lag lengths and the common scale $e$. Following Hiemstra and Jones (1994) and relying on the results of their Monte Carlo simulation, we set the values as $m=1$, lag length $=1, \ldots, 8$ and $e=1.5 \sigma$. Then, we apply the model again by employing the residuals of a bivariate VAR model including the monetary aggregate and the oil price. Table 4 presents the results.

Table 4 Nonparametric (Hiemstra-Jones) nonlinear causality tests

\begin{tabular}{|c|c|c|c|c|c|c|c|c|c|}
\hline \multirow[b]{2}{*}{ Lags } & \multicolumn{2}{|c|}{$\mathrm{OP} \rightarrow \mathrm{MA}$} & \multicolumn{2}{|c|}{$\mathrm{MA} \rightarrow \mathrm{OP}$} & \multirow[b]{2}{*}{ Lags } & \multicolumn{2}{|c|}{$\mathrm{OP} \rightarrow \mathrm{MA}$} & \multicolumn{2}{|c|}{$\mathrm{MA} \rightarrow \mathrm{OP}$} \\
\hline & $\mathrm{CS}$ & TVAL & $\mathrm{CS}$ & TVAL & & $\mathrm{CS}$ & TVAL & $\mathrm{CS}$ & TVAL \\
\hline Brazil & & & & & Sweden & & & & \\
\hline 1 & 0.0068 & 0.1009 & 0.0085 & 0.1257 & 1 & 0.0181 & 0.2383 & -0.0094 & -0.1244 \\
\hline 2 & 0.0117 & 0.1724 & 0.0103 & 0.1520 & 2 & 0.0344 & 0.4514 & -0.0122 & -0.1607 \\
\hline 3 & 0.0127 & 0.1853 & 0.0136 & 0.1989 & 3 & 0.0364 & 0.4766 & 0.0016 & 0.0210 \\
\hline 4 & 0.0127 & 0.1853 & 0.0226 & 0.3293 & 4 & 0.0554 & 0.7236 & 0.0137 & 0.1786 \\
\hline 5 & 0.0126 & 0.1832 & 0.0294 & 0.4282 & 5 & 0.0618 & 0.8036 & 0.0220 & 0.2872 \\
\hline 6 & 0.0163 & 0.2374 & 0.0361 & 0.5240 & 6 & 0.0564 & 0.7318 & 0.0486 & 0.6309 \\
\hline 7 & 0.0215 & 0.3115 & 0.0450 & 0.6518 & 7 & 0.0594 & 0.7677 & 0.0841 & 1.0872 \\
\hline 8 & 0.0251 & 0.3626 & 0.0528 & 0.7615 & 8 & 0.0563 & 0.7255 & 0.1208 & $1.5567 *$ \\
\hline Denmark & & & & & US & & & & \\
\hline 1 & 0.0196 & 0.3503 & 0.0226 & 0.4031 & 1 & 0.0632 & 1.1376 & 0.0561 & 1.0107 \\
\hline 2 & 0.0949 & $1.6913 * *$ & 0.0377 & 0.6713 & 2 & 0.1071 & $1.9265 * *$ & 0.0956 & $1.7184^{* *}$ \\
\hline 3 & 0.1333 & $2.3701 * * *$ & 0.0501 & 0.8921 & 3 & 0.1355 & $2.4315^{* * *}$ & 0.1003 & $1.7998 * *$ \\
\hline 4 & 0.1525 & $2.7074 * * *$ & 0.0350 & 0.6215 & 4 & 0.1510 & $2.7059 * * *$ & 0.0972 & $1.7425 * *$ \\
\hline 5 & 0.1504 & $2.6661 * * *$ & 0.0172 & 0.3048 & 5 & 0.1471 & $2.6318 * * *$ & 0.0833 & $1.4914 *$ \\
\hline 6 & 0.1482 & $2.6222 * * *$ & -0.0056 & -0.0990 & 6 & 0.1344 & $2.4006^{* * *}$ & 0.0708 & 1.2651 \\
\hline 7 & 0.1624 & $2.8697 * * *$ & -0.0293 & -0.5190 & 7 & 0.1223 & $2.1826 * *$ & 0.0561 & 1.0007 \\
\hline 8 & 0.1757 & $3.0999 * * *$ & -0.0504 & -0.8895 & 8 & 0.1143 & $2.0354 * *$ & 0.0433 & 0.7722 \\
\hline Germany & & & & & Canada & & & & \\
\hline 1 & 0.0437 & 0.7805 & 0.0412 & 0.7350 & 1 & 0.0552 & 0.9891 & 0.0265 & 0.4742 \\
\hline 2 & 0.0839 & $1.4943 *$ & 0.0560 & 0.9981 & 2 & 0.0912 & $1.6289 *$ & 0.0505 & 0.9021 \\
\hline 3 & 0.1359 & $2.4173 * * *$ & 0.0826 & $1.4686^{*}$ & 3 & 0.1003 & $1.7901^{* *}$ & 0.0478 & 0.8532 \\
\hline 4 & 0.1558 & $2.7656 * * *$ & 0.1001 & $1.7767 * *$ & 4 & 0.0822 & $1.4647 *$ & 0.0450 & 0.8017 \\
\hline 5 & 0.1541 & $2.7315^{* * *}$ & 0.1012 & $1.7950 *$ & 5 & 0.0688 & 1.2234 & 0.0421 & 0.7498 \\
\hline 6 & 0.1386 & $2.4525 * * *$ & 0.0935 & $1.6555^{* *}$ & 6 & 0.0516 & 0.9174 & 0.0285 & 0.5059 \\
\hline 7 & 0.1261 & $2.2276 * *$ & 0.0827 & $1.4615^{*}$ & 7 & 0.0404 & 0.7167 & 0.0444 & 0.7882 \\
\hline 8 & 0.1124 & $1.9824 * *$ & 0.0696 & 1.2290 & 8 & 0.0338 & 0.5986 & 0.0646 & 1.1444 \\
\hline Italy & & & & & Norway & & & & \\
\hline 1 & 0.0063 & 0.0865 & -0.0036 & -0.0500 & 1 & 0.0234 & 0.3648 & 0.0148 & 0.2304 \\
\hline 2 & 0.0074 & 0.1005 & 0.0154 & 0.2086 & 2 & 0.0728 & 1.1285 & 0.0165 & 0.2562 \\
\hline 3 & 0.0048 & 0.0647 & 0.0165 & 0.2235 & 3 & 0.0997 & $1.5413^{*}$ & 0.0216 & 0.3353 \\
\hline 4 & 0.0041 & 0.0559 & 0.0131 & 0.1764 & 4 & 0.1282 & $1.9781^{* *}$ & 0.0523 & 0.8081 \\
\hline 5 & -0.0288 & -0.3869 & 0.0108 & 0.1460 & 5 & 0.1490 & $2.2948 * *$ & 0.0758 & 1.1669 \\
\hline 6 & -0.0494 & -0.6615 & 0.0229 & 0.3074 & 6 & 0.1467 & $2.2543 * *$ & 0.0882 & $1.3550 *$ \\
\hline
\end{tabular}




\begin{tabular}{lllll|lllll}
\hline 7 & -0.0796 & -1.0620 & 0.0263 & 0.3514 & 7 & 0.1331 & $2.0413^{* *}$ & 0.1105 & $1.6943^{* *}$ \\
8 & -0.1055 & -1.4042 & 0.0038 & 0.0514 & 8 & 0.1089 & 1.6664 & 0.1294 & $1.9799^{* *}$ \\
& & & & & & & & \\
Netherlands & & & & & & & & \\
1 & 0.0482 & 0.8686 & 0.0614 & 1.1062 & 1 & 0.0550 & 0.9857 & 0.0690 & 1.2372 \\
2 & 0.1095 & $1.9683^{* *}$ & 0.1161 & $2.0872^{* *}$ & 2 & 0.1023 & $1.8305^{* *}$ & 0.1069 & $1.9123^{* *}$ \\
3 & 0.1371 & $2.4613^{* * *}$ & 0.1368 & $2.4561^{* * *}$ & 3 & 0.1136 & $2.0296^{* *}$ & 0.1060 & $1.8934^{* *}$ \\
4 & 0.1437 & $2.5758^{* * *}$ & 0.1330 & $2.3839^{* * *}$ & 4 & 0.1086 & $1.9376^{* *}$ & 0.0952 & $1.6988^{* *}$ \\
5 & 0.1398 & $2.5020^{* * *}$ & 0.1015 & $1.8168^{* *}$ & 5 & 0.1039 & $1.8508^{* *}$ & 0.0698 & 1.2445 \\
6 & 0.1393 & $2.4882^{* * *}$ & 0.0766 & $1.3690^{*}$ & 6 & 0.0900 & 1.6008 & 0.0430 & 0.7661 \\
7 & 0.1366 & $2.4368^{* * *}$ & 0.0458 & 0.8174 & 7 & 0.0791 & 1.4045 & -0.0036 & -0.0654 \\
8 & 0.1260 & $2.2441^{* *}$ & 0.0264 & 0.4705 & 8 & 0.0738 & 1.3084 & -0.0325 & -0.5773 \\
& & & & & & & & & \\
\end{tabular}

\footnotetext{
This table reports the results of the nonparametric nonlinear Baek and Brock (1992) test, as modified by Hiemstra and Jones (1994). CS and TVAL are the differences between the conditional probabilities and the standardized test statistics, respectively. Canada, Norway and Mexico are net oil producer countries and the remainder are net oil consumer countries.*, ${ }^{* *}$ and ${ }^{* * *}$ indicate significance at the $10 \%, 5 \%$ and $1 \%$ level, respectively.
}

The results indicate that in both panels, there is evidence demonstrating the nonlinear causal effects of oil price changes on the monetary aggregates. This is evident in all of the net oil producing countries and nearly half of the sample net oil consuming countries. Consequently, it appears more likely that the causal effects of global oil price changes on monetary aggregates are nonlinear in net oil producing countries as against net oil consuming countries. Table 4 shows that the nonlinear causal effects of the oil price changes on monetary aggregates are evident in Germany, the Netherlands, and the US. The relevant test statistics are highly significant and demonstrate that the causal effects of the oil price changes on the monetary aggregates are persistent for 7 months with a 2-month lag. In the net oil producing countries, bilateral causation is evident in Norway and Mexico. In this case, the causation of global oil price changes on the monetary aggregate is persistent for 5 months with a 3-month lag in Norway and 4 months with a 2-month lags in Mexico.

There is also strong evidence demonstrating unilateral nonlinear causality among net oil consuming countries for Denmark and among net oil producing countries for Canada. The nonlinear causal effects of the oil price changes in Denmark, which are mostly significant at the 1 percent level, persist for 7 months. Such evidence is also evident, although weaker, at the 10 percent level in Canada with a 2month lag and persistent for 3 months.

Altogether, the nonparametric nonlinear causality tests reveal that there is stronger evidence in net oil producing countries concerning nonlinear causal relationships between global oil price changes and monetary aggregates. Furthermore, the nonlinear effects of global oil price changes on monetary aggregates are persistent over the longer term in net oil consuming countries. It thus seems that contrary to Carlstrom and Fuerst (2006) and Hamilton and Herrera (2004), monetary policy has widely been used in both most net oil consuming and net oil producing economies in response to oil price movements.

\subsection{Parametric model}

The nonparametric nonlinear causality test implemented provides strong evidence of the unilateral and bilateral causal relationships between oil prices and monetary aggregates within some net oil consuming and producing countries. The results are strong enough in themselves to confirm the existence of such direct causation. However, to capture asymmetry among the causal relationships and to confirm the nonparametric nonlinear test results, we also use a parametric model. The test is similar to the linear Granger causality test. However, it contains the Mackey-Glass model process with special parameters estimated using ordinary least squares method. In order to examine the existence of nonlinear causality between oil price changes and consumer price index, we start with the following models: 


$$
\begin{aligned}
& D O P_{t}=\alpha_{11} \frac{D O P_{t-\tau_{1}}}{1+D O P_{t-\tau_{1}}^{\mathrm{C}_{1}}}-\delta_{11} D O P_{t-1}+\alpha_{12} \frac{D M A_{t-\tau_{2}}}{1+D M A_{t-\tau_{2}}^{\mathrm{C}_{2}}}-\delta_{12} D M A_{t-1}+\varepsilon_{t} \\
& D M A_{t}=\alpha_{21} \frac{D O P_{t-\tau_{1}}}{1+D O P_{t-\tau_{1}}^{\mathrm{C}_{1}}}-\delta_{21} D O P_{t-1}+\alpha_{22} \frac{D M A_{t-\tau_{2}}}{1+D M A_{t-\tau_{2}}^{\mathrm{C}_{2}}}-\delta_{22} D M A_{t-1}+u_{t}
\end{aligned}
$$

where $D M A_{t}$ and $D O P_{t}$ are the first differences of the monetary aggregate and the oil price, respectively. Also, $\tau=\max \left(\tau_{1}, \tau_{2}\right)$ is the calculated integer delays, $\mathrm{c}$ is the constant and $t=\tau$, $\tau+$ $1, \ldots, N$. The parameters $\alpha$ and $\delta$, indicate the linear and nonlinear effects of the causal variable on dependent variable, respectively. Finally, the two error terms $u_{t}$ and $\varepsilon_{t}$ are assumed to be $N(0,1)$. We select the integer delays $\tau_{i}$ and constants $c_{i}$ prior to the model estimation using the Schwarz criterion and likelihood ratio. If the oil price is defined to nonlinear Granger cause the monetary aggregate, $\alpha_{11}$ should be significantly different from zero (the null hypothesis). Thus, we need to estimate each equation once with no constraint and once with the constraint of a zero value for $\alpha_{11}$ (and $\alpha_{22}$ ). Assuming $\hat{\vartheta}$ and $\hat{\mu}$ are the residuals of the unconstrained and constrained Mackey-Glass models, respectively we calculate a Fisher-distributed statistic as below:

$$
S_{F}=\frac{\left(S_{c}-S_{u}\right) / n_{c}}{S_{u} /\left(T-n_{u}-1\right)} \sim F\left(n_{c}, T-n_{u}-1\right)
$$

where $S_{u}=\sum_{t=1}^{T} \hat{\vartheta}^{2}, S_{c}=\sum_{t=1}^{T} \hat{\mu}^{2}, n_{u}=4$ due to existence of four parameters in the Mackey-Glass model and $n_{c}=1$ because there is one parameter needed to be zero when estimating constrained model. To conduct the parametric nonlinear Mackey-Glass test, we first need to select the models' parameters using Schwarz criterion and likelihood ratio. Table 5 details the results.

The first and the second columns in Table 5 indicate the lag orders employed in Equations 4 and 5. The third and fourth columns in this same table provide the powers used in Equations 4 and 5. The lag lengths in terms of the effects of the oil price changes on the monetary aggregates range from 3 months in Sweden and Italy to 9 months in Canada and Mexico. These lags have important implications for policy decision makers when considering the time needed for the monetary aggregate to respond to the oil price change. This delay in the net oil producing countries seems to be slightly longer than in the net oil consuming countries, from an average of nearly 8 months in the former compared with nearly 5 months on average in the latter. We use the estimated lag orders as preestimates when estimating Equations 4 and 5.

Table 5 Parameter-prior selection in the $\mathrm{M}-\mathrm{G}$ model

\begin{tabular}{lcccc}
\hline Country & $\tau_{1}$ & $\tau_{2}$ & $\mathrm{c}_{1}$ & $\mathrm{c}_{2}$ \\
\hline Brazil & 5 & 1 & 4 & 7 \\
Denmark & 5 & 1 & 1 & 1 \\
Germany & 5 & 1 & 10 & 10 \\
Italy & 3 & 1 & 5 & 1 \\
Netherlands & 6 & 1 & 10 & 2 \\
Sweden & 3 & 1 & 3 & 8 \\
US & 6 & 1 & 1 & 2 \\
Canada & 9 & 1 & 2 & 1 \\
Norway & 5 & 1 & 10 & 1 \\
Mexico & 9 & 1 & 3 & 1 \\
\hline In this table, $\tau_{1}$ and $\tau_{2}$ are the optimal integer delay variables for \\
the causality from OP to MA, and for the causality from MA to \\
OP, respectively. $\mathrm{c}_{1}$ and $\mathrm{c}_{2}$ are the power of the lagged values of \\
OP and MA, respectively.
\end{tabular}

The results of our nonlinear parametric causality test presented in Table 6 indicate strong unilateral nonlinear causality running from oil price changes to the monetary aggregates. The first point is that the 
results confirm the outcomes of the nonparametric model, except in the case of Norway. Similar to the nonparametric model, oil price changes Granger cause the monetary aggregate in Denmark, Germany, the Netherlands, and the US. Similar causation in net oil producing countries is significant only for Canada and Mexico. The statistics for net oil producing countries are generally more statistically significant than for the net oil consuming countries. This confirms the nonparametric model results, which indicated that the monetary aggregates in net oil producing countries have great opportunity to respond nonlinearly to global oil price movements. Finally, as opposed to the nonparametric model, reverse nonlinear causation is not evident except in Italy.

Table 6 Symmetric nonlinear causality test

\begin{tabular}{lcccc}
\hline \multirow{2}{*}{ Country } & \multicolumn{2}{c}{ H0: OP does not cause MA } & \multicolumn{2}{c}{ H0: MA does not cause OP } \\
\cline { 2 - 5 } & F-statistic & Probability & F-statistic & Probability \\
\hline Brazil & 0.2212 & 0.6385 & 1.5636 & 0.2124 \\
Denmark & 5.4768 & 0.0198 & 2.2669 & 0.1331 \\
Germany & 4.6151 & 0.0012 & 0.1880 & 0.9445 \\
Italy & 1.0987 & 0.3585 & 37.3992 & 0.0000 \\
Netherlands & 4.7036 & 0.0010 & 0.4401 & 0.7796 \\
Sweden & 1.3081 & 0.2542 & 0.5691 & 0.4515 \\
US & 5.7841 & 0.0167 & 0.0371 & 0.8473 \\
Canada & 7.5949 & 0.0061 & 2.4086 & 0.1216 \\
Norway & 0.3670 & 0.5451 & 1.1678 & 0.2809 \\
Mexico & 9.9967 & 0.0017 & 2.2226 & 0.1369 \\
\hline
\end{tabular}

Considering both parametric and nonparametric models, we now know that global oil price changes nonlinearly affect monetary aggregates in both net oil consuming and producing countries. In the next subsection, we use nonlinear asymmetric tests the effective direction of these changes.

\subsection{Asymmetric model}

Using the parametric nonlinear causality model presented in the last subsection, we now test the asymmetry in the causal effects of global oil price changes on monetary aggregates. To do this, we first separate the positive and negative values in the oil price data. That is, $\left(O P_{t}, M A_{t}\right)$ is used as an observation in the Mackey-Glass process if $O P_{t-\tau} \geq 0$. We then estimate Equations 4 and 5 using the separate data. Tables 7 and 8 provide the symmetric test results.

Table 7

Asymmetric nonlinear causality test for negative changes in the causal variable.

\begin{tabular}{cccc}
\hline \multicolumn{2}{c}{ H0: OP does not cause MA } & \multicolumn{2}{c}{ H0: MA does not cause OP } \\
\hline F-statistic & Probability & F-statistic & Probability \\
\hline 0.1813 & 0.6712 & 0.1838 & 0.6763 \\
0.6620 & 0.4232 & 0.1069 & 0.7461 \\
0.7355 & 0.5732 & 0.0189 & 0.9992 \\
N/A & $\ldots$ & N/A & $\ldots$ \\
0.5090 & 0.7292 & 0.2323 & 0.9148 \\
0.0510 & 0.8288 & 0.6904 & 0.4089 \\
0.3474 & 0.5606 & 0.0462 & 0.8314 \\
0.3409 & 0.5601 & 0.0272 & 0.8702 \\
0.9796 & 0.3246 & 0.7232 & 0.4076 \\
0.8528 & 0.3645 & 0.0349 & 0.8519 \\
\hline
\end{tabular}

Table 7 displays nonlinear monetary responses to the negative global oil price changes. The results show that negative oil price changes have no effect on the monetary aggregates, neither in net oil producing nor in net oil consuming countries. In the case of Italy, there is insufficient data to run Equations 4 and 5. The results in Table 8 signify that the nonlinear causal effect of global oil price changes on monetary 
aggregates is strongly asymmetric in that only positive oil price changes have an effect. Such asymmetric responses of monetary aggregates to global oil price changes have important implications for policy decision makers. For instance, as the monetary aggregates respond only to positive oil price changes, the same applies for other monetary variables, such as interest rates. This concurs with the results in Sotoudeh and Worthington (2014) such that the effect of the oil price on the short-term real interest rate is asymmetric and only for positive oil price changes.

Table 8 Asymmetric nonlinear causality test for positive changes in the causal variable

\begin{tabular}{lcccc}
\hline \multirow{2}{*}{ Country } & \multicolumn{2}{c}{ H0: OP does not cause MA } & \multicolumn{2}{c}{ H0: MA does not cause OP } \\
\cline { 2 - 5 } & F-statistic & Probability & F-statistic & Probability \\
\hline Brazil & 0.1292 & 0.7198 & 1.5832 & 0.2097 \\
Denmark & 5.2063 & 0.0232 & 2.2076 & 0.1384 \\
Germany & 4.2114 & 0.0061 & 0.81093 & 0.5256 \\
Italy & 1.2005 & 0.3256 & 2.3803 & 0.000 \\
Netherlands & 4.8160 & 0.0028 & 0.3655 & 0.8317 \\
Sweden & 1.2150 & 0.2718 & 0.0899 & 0.7647 \\
US & 5.7854 & 0.0167 & 0.1385 & 0.7102 \\
Canada & 7.9267 & 0.0054 & 2.3393 & 0.1272 \\
Norway & 0.1706 & 0.6801 & 1.0604 & 0.3042 \\
Mexico & 9.5426 & 0.0022 & 2.0201 & 0.1563 \\
\hline
\end{tabular}

\section{Conclusion}

In this paper, we compared the causal effects of global oil price movements on monetary aggregates in net oil consuming and net oil producing countries. Our results indicated significant linear causality running from global oil price changes to monetary aggregates within both panels of net oil consuming and net oil producing countries. At least some of these, mostly net oil consuming countries, exhibited bilateral causal relationships. However, because of the linearity assumptions in traditional Granger causality tests and given evidence elsewhere of nonlinear causality among macroeconomic variables, these linear causality test results may not be reliable. Consequently, we employed two types of nonlinear causality tests. The interesting point is that while the results of both nonlinear models generally concurred, there are mostly bilateral and rarely unilateral causal relationships between oil price changes and monetary aggregates among both net oil consuming and net oil producing countries. Lastly, using an asymmetric version of the nonlinear parametric model we found that the causal effects of global oil price changes on monetary aggregates are strongly asymmetric, with monetary aggregates responding only to positive oil price changes.

Our findings have important implications as follows. Firstly, although a large body of research focuses on the indirect monetary responses to the inflationary effects of oil price changes, our findings provide strong evidence of the direct causal effects of oil price changes on monetary aggregates. We confirm that in both net oil producing and net oil consuming countries, oil price changes are directly responsible for changes in monetary aggregates. This is important for policymakers when implementing monetary policy. Secondly, our results show that monetary aggregates respond to oil price changes with a lag of two months or more. This period seems longer in net oil producing countries.

Finally, although we find significant nonlinear causation, mainly from oil price changes to the monetary aggregate in both the net oil consuming and net oil producing countries, we note two important points. To start with, the nonlinear models we applied in this paper provide no guidance on the source of nonlinearities. This may require specifically parameterized structural models. Further, it is not possible to determine whether significant nonlinear predictive power is evidence of positive or negative nonlinear causality. Beside the evidence that nonlinear models presented, it is worth noting that linear causality tests may provide an incorrect assessment of the true relationship between oil price movements and monetary aggregate, which are of nonlinear nature with respect to our results, and may 
suggest misleading policy actions. For further study, we recommend an even more powerful statistical test, which accounts for not only nonlinearity, asymmetry and time-variations, but also the conditional heteroscedasticity of the VAR model variances.

\section{References}

Abderrezak A (2005) Oil price shocks—money supply causality: Some evidence from Algeria. The Journal of North African Studies 10(2): 173-181.

Ajmi AN, Montasser GE, Nguyen DK (2013) Testing the relationships between energy consumption and income in G7 countries with nonlinear causality tests. Economic Modelling 35: 126-133.

Baek EG, Brock WA (1992) A general test for nonlinear Granger causality: Bivariate model. In: Working paper. Ames: Iowa State University and Madison: University of Wisconsin.

Balke NS, Brown SPA, Yucel MK (1998). Crude oil and gasoline prices: An asymmetric relationship? Economic Review Federal Reserve Bank of Dallas: 2-11.

Banca d'Italia (2013) Statistics. Available at http://bip.bancaditalia.it.

Barsky R, Kilian L (2004) Oil and the macroeconomy since the 1970's. Journal of Economic Perspectives 18(4): 115-134.

Bell DNF (1996) A non-parametric approach to non-linear causality testing. Economics letters 51(1): 7-18.

Bernanke BS, Gertler M, Watson M, Sims CA, Friedman BM (1997) Systematic monetary policy and the effects of oil price shocks. Brookings Papers on Economic Activity: 91-157.

Bernanke BS, Ilian M (1998) Measuring monetary policy. The Quarterly Journal of Economics 113(3): 869-902.

Bruno M, Sachs J (1985) Economics of worldwide stagflation. Harvard University Press, Cambridge.

Carlstrom CT, Fuerst TS (2006) Oil Prices, Monetary Policy, and Counterfactual Experiments. Journal of Money, Credit and Banking 38(7): 1945-1958.

Chen Y, Rangarajan G, Feng J, Ding M (2004) Analyzing multiple nonlinear time series with extended Granger causality. Physics Letters A 324(1): 26-35.

Chiou-Wei SZ, Chen CF, Zhu Z (2008) Economic growth and energy consumption revisited — Evidence from linear and nonlinear Granger causality. Energy Economics 30(6): 3063-3076.

Cologni A, Manera M (2008) Oil prices, inflation and interest rates in a structural cointegrated VAR model for the G-7 countries. Energy Economics 30(3): 856-888.

Davis SJ, Haltiwanger J (2001) Sectoral job creation and destruction responses to oil price changes. Journal of Monetary Economics 48(3): 465-512.

De Nederlandsche Bank (2013) Domestic MFI-statistics (monetary). Available at http://www.statistics.dnb.nl.

DeJong DN (1992) The power problems of unit root tests in time series with autoregressive errors. Journal of Econometrics 53(1): 323-341.

Denker M, Keller G (1983) On U-statistics and v. mise' statistics for weakly dependent processes. Zeitschrift für Wahrscheinlichkeitstheorie und Verwandte Gebiete 64(4): 505-522.

Deutsche Bundesbank (2013) Statistics. Available at http://www.bundesbank.de/Navigation/EN/Statistics.

Hamilton JD (1983) Oil and the macroeconomy since world war II. Journal of Political Economy 91(2): 228-248.

Hamilton JD (1988) Are the macroeconomic effects of oil-price changes symmetric?: A comment. Carnegie-Rochester Conference Series on Public Policy 28(0): 369-378.

Hamilton JD (1996) This is what happened to the oil price-macroeconomy relationship. Journal of Monetary Economics 38(2): 215-220.

Hamilton JD (2003) What is an oil shock? Journal of Econometrics 113(2): 363-398.

Hamilton JD (2011) Nonlinearities and the macroeconomic effects of oil prices. Macroeconomic Dynamics 15(3): 364-378.

Hamilton JD, Herrera AM (2004) Oil shocks and aggregate macroeconomic behavior: The role of monetary policy. Journal of Money, Credit and Banking 36(2): 265-286.

Hiemstra C, Jones JD (1994) Testing for linear and nonlinear Granger causality in the stock price-volume relation. The Journal of Finance 49(5): 1639-1664.

Hiemstra C, Kramer C (1997) Nonlinearity and endogeneity in macro-asset pricing. Studies in Nonlinear Dynamics and Econometrics 2(3): 1-17.

Hooker MA (1996) What happened to the oil price-macroeconomy relationship? Journal of Monetary Economics 38(2): 195213.

Hooker MA (1999) The maturity structure of term premia with time-varying expected returns. The Quarterly Review of Economics and Finance 39(3): 391-407.

Hoover KD, Perez SJ (1994) Post hoc ergo propter once more an evaluation of ‘does monetary policy matter?' in the spirit of James Tobin. Journal of Monetary Economics 34(1): 47-74.

International Energy Agency (IEA) (2013) Statistics. Available at http://www.iea.org/stats/index.asp.

Jiménez-Rodríguez R (2011) Macroeconomic structure and oil price shocks at the industrial level. International Economic Journal 25(1): 173-189. 
Jiménez-Rodríguez R, Sánchez M (2005) Oil price shocks and real GDP growth: empirical evidence for some OECD countries. Applied Economics 37(2): 201-228.

Jones DW, Leiby PN, Paik IK (2004) Oil price shocks and the macroeconomy: What has been learned since 1996. The Energy Journal 25(2): 1-32.

Kanas A, Ma Y (2000) Testing for a nonlinear relationship among fundamentals and exchange rates in the ERM. Journal of International Money and Finance 19(1): 135-152.

Keane MP, Prasad ES (1996) The employment and wage effects of oil price changes: A sectoral analysis. The Review of Economics and Statistics 78(3): 389-400.

Kilian L (2008) A comparison of the effects of exogenous oil supply shocks on output and inflation in the G7 countries. Journal of the European Economic Association 6(1): 78-121.

Kilian L (2009) Not all oil price shocks are alike: disentangling demand and supply shocks in the crude oil market. The American Economic Review 99(3): 1053-1069.

Kilian L, Park C (2009) The impact of oil price shocks on the U.S. stock market. International Economic Review 50(4): 1267-1287.

Korhonen I, Ledyaeva S (2010) Trade linkages and macroeconomic effects of the price of oil. Energy Economics 32(4): 848856.

Kyrtsou C, Labys WC (2006) Evidence for chaotic dependence between US inflation and commodity prices. Journal of Macroeconomics 28(1): 256-266.

Leduc S, Sill K (2004) A quantitative analysis of oil-price shocks, systematic monetary policy, and economic downturns. Journal of Monetary Economics 51(4): 781-808.

Lee BR, Lee K, Ratti RA (2001) Monetary policy, oil price shocks, and the Japanese economy. Japan and the World Economy 13(3): 321-349.

Lee CC, Chang CP (2007) Energy consumption and GDP revisited: A panel analysis of developed and developing countries. Energy Economics 29(6): 1206-1223.

Lee K, Ni S (2002) On the dynamic effects of oil price shocks: a study using industry level data. Journal of Monetary Economics 494: 823-852.

Leeper EM, Zha T (2003) Modest policy interventions. Journal of Monetary Economics 50(8): 1673-1700.

Li J (2006) Testing Granger causality in the presence of threshold effects. International Journal of Forecasting 22(4): 771780.

Mackey MC, Glass L (1977) Oscillation and chaos in physiological control systems. Science 197(4300): $287-289$.

Miguel C, Manzano B, Martin-Moreno JM, Ruiz J (2009) Disentangling the effects of oil shocks: The role of rigidities and monetary policy. The Energy Journal 30(SI2): 193-216.

Skalin J, Teräsvirta T (1999) Another look at Swedish business cycles, 1861-1988. Journal of Applied Econometrics 14(4): 359-378.

Schwert GW (1989) Tests for unit roots: a Monte Carlo investigation. Journal of Business and Economic Statistics 7(2): 147159.

Seifritz W, Hodgkin J (1991) Nonlinear dynamics of the per capita energy consumption. Energy 16(3): 615-620.

Sotoudeh MA, Worthington AC (2014) Nonlinear interest rate effects of global oil price changes: the comparison of net oilconsuming and net oil-producing countries. Applied Economics Letters: DOI: 10.1080/13504851.2014.969821.

World Bank (2013) Crude oil price, WTI, \$/bbl. Available at http://www.quandl.com/worldbank.

Wang Y, Wu C, Yang L (2013) Oil price shocks and stock market activities: Evidence from oil-importing and oil-exporting countries. Journal of Comparative Economics 41(4): 1220-1239.

Wu MH, Ni YS (2011) The effects of oil prices on inflation, interest rates and money. Energy 36(7): 4158-4164. 